\title{
Exploring Awareness Behaviours and Collaboration Activities in Learning Groups
}

\author{
Reem Al Ashaikh \\ Centre for $\mathrm{HCl}$ Design \\ City University London \\ reem.al-ashaikh.1@city.ac.uk
}

\author{
Stephanie Wilson \\ Centre for $\mathrm{HCl}$ Design \\ City University London \\ S.M.Wilson@city.ac.uk
}

\author{
Sara Jones \\ Centre for $\mathrm{HCl}$ Design \\ City University London \\ S.V.jones@city.ac.uk
}

\begin{abstract}
Collaborative learning is a useful approach in which learners work jointly to achieve learning goals. Awareness plays a significant role in promoting collaboration opportunities and enhancing the effectiveness of the collaborative learning. This poster reports a study to explore awareness behaviours in a long-term collaborative project. The research questions focus on awareness behaviours, the changes in awareness over time, and the applications used to communicate and collaborate. Three main data collection methods were used: observations, short interviews and questionnaires. Participants were students who were working on collaborative coursework for 6 weeks. Results show that different awareness types and behaviours were evident and activity awareness was higher at the beginning of the collaborative project than it was towards the middle or the end. In addition, groups used different general-purpose applications to support their collaborations.
\end{abstract}

Awareness, Activity Awareness, Collaborative Learning Project, Long-term Collaborative Project

\section{INTRODUCTION}

Collaborative learning is an effective approach to support the learning process (Dillenbourg, 1999). It can be described as the situation in which a group of learners work together to complete a common task (Dillenbourg, 1999). Awareness is a useful concept in promoting collaboration opportunities and improving the effectiveness of collaborative learning (Paletta \& Herrero, 2011). There are different types of awareness such as activity awareness and situation awareness. Carroll et al. (2006) defined activity awareness as "a dynamic process in which a variety of information is constantly shared, tested, and updated to guide group behavior". Previous studies have reported on the significant role of awareness in enhancing collaboration in groups (Gutwin et al., 2004) (Convertino et al., 2004); however studies to understand awareness in collaborative groups for longitudinal learning projects are limited. Convertino et al. (2004) stated that many breakdowns in longitudinal collaboration happen because of a lack of activity awareness.

An exploratory study was undertaken to understand awareness in groups working on a longitudinal project. The main research questions were:

(i) What awareness behaviours and awareness types were exhibited in the learning groups? (ii) What collaboration activities were identified in the learning groups?

(iii) Did awareness and collaboration change over time?

(iv) What applications and tools did the groups use during meetings and to collaborate afterwards?

\section{METHODOLOGY}

As the research questions were open-ended and exploratory, a qualitative approach was adopted. Three main data collection methods were used; observations, short interviews and questionnaires.

\subsection{Participants}

The participants were a convenience sample of MSc students who were working on a collaborative coursework for 6 weeks. The coursework involved the design of an interactive device as part of an introductory module on interaction design. Group members had not worked together previously and had different educational backgrounds, skills, and experiences. Five groups participated in the study with 3 or 4 members in each group and a total of 17 participants. Each group determined its own working methods and selected various software applications to collaborate. 


\subsection{Data collection methods}

Observations: groups were observed at least twice for about 30 minutes during their regular meetings in the City University premises.

Interviews: each participant was interviewed individually twice for about 4 to 7 minutes, except for one group, where each member was interviewed once only. The interview questions were mostly designed to probe awareness, collaboration, and tools they used.

Questionnaires: each participant was given 2 questionnaires; one at the beginning of the study to collect factual data; and the other at the end of the project which used Likert-scale questions to assess students' awareness and satisfaction towards their learning experience and learning preferences. Table 1 shows the timeline of the collected data.

Table 1: The timeline for data collection (Obs = observation, Int = interview, Que = questionnaire)

\begin{tabular}{|l|l|l|l|l|l|l|}
\hline \multirow{2}{*}{ Groups } & \multicolumn{7}{|c|}{ Weeks } \\
\cline { 2 - 7 } & 1 & 2 & 3 & 4 & 5 & 6 \\
\hline$A$ & $\begin{array}{l}\text { Obs1 } \\
\text { Int1 } \\
\text { Que1 }\end{array}$ & & $\begin{array}{l}\text { Obs2 } \\
\text { Int2 }\end{array}$ & & & Que2 \\
\hline$B$ & $\begin{array}{l}\text { Obs1 } \\
\text { Int1 } \\
\text { Que1 }\end{array}$ & & $\begin{array}{l}\text { Obs2 } \\
\text { Int2 }\end{array}$ & Obs3 & & Que2 \\
\hline C & & $\begin{array}{l}\text { Obs1 } \\
\text { Que1 }\end{array}$ & & Int1 & $\begin{array}{l}\text { Int1 } \\
\text { Obs2 }\end{array}$ & Que2 \\
\hline D & & $\begin{array}{l}\text { Obs1 } \\
\text { Que1 }\end{array}$ & Int1 & $\begin{array}{l}\text { Obs2 } \\
\text { Int2 }\end{array}$ & & Que2 \\
\hline$E$ & & $\begin{array}{l}\text { Obs1 } \\
\text { Que1 }\end{array}$ & Int1 & & $\begin{array}{l}\text { Obs2 } \\
\text { Int2 }\end{array}$ & $\begin{array}{l}\text { Int2 } \\
\text { Que2 }\end{array}$ \\
\hline
\end{tabular}

\subsection{Data analysis}

Mixed approaches were used to code and analyse the qualitative data: top-down and bottom-up approaches. The coded data were collaboration activities and styles, awareness behaviours, awareness types, and tools and applications used. Colour coding was used to differentiate between different levels of activity awareness. The "accuracy" of participants' activity awareness was explored by comparing their answers to interview questions about the activity of their colleagues against the reality of what those colleagues had been doing.

\section{RESULTS AND DISCUSSION}

Different types of awareness were evident including activity awareness, skills awareness, current-state awareness, next-step awareness, and time awareness. Some of these emergent awareness types were new and have not been reported in the literature, such as skills awareness and next-step awareness.
In addition, several awareness-promoting behaviours were identified in the collaborative groups, such as reviewing work, asking direct questions, and looking at Google drive or notes.

Results showed that activity awareness was higher at the beginning of the collaborative project than at the middle or the end. In addition, work reviews were higher at the beginning than near the end.

Collaboration activities included discussion, suggesting, and helping each other to complete a task.

Groups used different existing applications during their collaborations such as Email, WhatsApp, Google drive and Hangout. It seemed that participants preferred to use general-purpose applications to collaborate rather than trying to use any specific collaborative learning environment.

A synthesis of these results will deliver a model of awareness that will be introduced to reinforce awareness throughout learning projects.

\section{CONCLUSIONS}

In conclusion, understanding awareness behaviours in collaborative learning groups will help to find out how technology could enhance awareness and support such collaborations. The next steps will focus on investigating different applications and tools that are specifically used in collaborative learning environments to determine their strengths and limitations in supporting awareness for longitudinal projects.

\section{REFERENCES}

Carroll, J. M., Rosson, M. B., Convertino, G., \& Ganoe, C. H. (2006) Awareness and teamwork in computer-supported collaborations. Interacting with Computers, 18(1). 21-46.

Convertino, G., Neale, D. C., Hobby, L., Carroll, J. M., \& Rosson, M. B. (2004) A Laboratory Method for Studying Activity Awareness. NordiCHI 'O4. October 23-27, 2004 Tampere, Finland. ACM. 313-322.

Dillenbourg, P. (1999) What do you mean by collaborative learning '?, 1. 1-15.

Gutwin, C., Penner, R., \& Schneider, K. (2004) Group awareness in distributed software development. Proceedings of the 2004 ACM conference on CSCW '04. November 6-10, 2004, Chicago, Illinois, USA. ACM. 72.

Paletta, M., \& Herrero, P. (2011) Learning to collaborate in distributed environments by means of an awareness-based artificial neural network. Neurocomputing, 74. 2603-2613. 